\title{
Comparison of Current Year (2019) Meteorological Parameters on the Basis of Long Term Climate Data of Bastar District
}

\author{
M. Kumar, A. Sanadya*, J. L. Choudhary, G. K. Das and H. C. Nada \\ Department of Agronomy, Indira Gandhi Krishi Vishwavidyalaya, \\ Raipur, GKMS, SGCARS, Jagdalpur, India \\ *Corresponding author
}

\section{Keywords}

Meteorological

Parameters, Long

Term Climate Data,

Bastar District

Article Info

Accepted:

04 October 2020

Available Online:

10 November 2020

\section{A B S T R A C T}

In year 2019 may be sais as an unique year which registered rainfall of $2313 \mathrm{~mm}$. Weather parameter trends of Jagdalpur $\left(19.0854^{\circ} \mathrm{N}\right.$ Latitude, $82.0183^{\circ} \mathrm{E}$ Longitude, elevation $552 \mathrm{~m}$ mean sea level) is analysed by MS - excel software package. Analysis of weather parameters viz. maximum and minimum temperature, rainfall, rainy days and relative humidity was done from 1980 to 2018 (39 years) and 2019. The results revealed that total annual rainfall and rainy days are comparatively more in 2019 as compared to past 39 years with a difference of $896 \mathrm{~mm}$ in rainfall with 8 more rainy days in year 2019. In case of mean maximum and mean minimum temperature, slight but effective changes are seen.

\section{Introduction}

Weather and climate play a vital role in agricultural production. In last few decades, the increased frequency of extreme climatic events has caused enormous damage to agriculture subsectors in general to India and particularly to Chhattisgarh. The 40 years 1980 to 2019 of available meteorological data shows that in year 2019 on $6^{\text {th }}$ September there was a $290 \mathrm{~mm}$ of rainfall received in a single day at Bastar. Raising temperature and increased drought events induced by changing climate have increased the need for efficient use of natural resources producing sufficient food and fibre for the growing population with changing consumption patterns from ever decreasing resources base requires strategic plans for efficient use of natural resources such as water, nutrients and photosynthetically active radiation (PAR). Water is considered as the second most limiting factor after land to increase food and fibre production. The two natural miracle reaction cation exchange and photosynthesis are responsible for life on mother planet. The cation exchange took place within the soil while photosynthesis above the soil surface. Since when we put the seed in the soil, the role of temperature and moisture started. It is essential for various chemicals and physiological reactions in plant and provides 
a medium where most cellular function take place. Soil water affects nutrients transformation from unavailable to available form or vice versa and thereby the total uptake amount. It also influences the availability of applied nutrients and efficiency through its effect on various nutrients and efficiency through its effect on various nutrients loss mechanisms such as volatilization, soil nutrients and PAR are also key factors in crop production. Plants usually suffer from nutrients deficiencies and more importantly a reduction in net photosynthetic assimilation rate under water stress. Better inception of PAR is needed for higher biomass production and grain yield, which is also hampered under water-limited environments.

The situation is expected to be further intensified in a future changing climate which urgently calls for efficient adaptation strategies to mitigate the negative impacts associated with these changes on crop production. Therefore, improving the efficiency of natural resources use continues to escalate as a topic of interest for crop and soil scientists.

In the recent years, priority is given to studies of climate change and climate fluctuations. The regional climate swings and variability have profound influence on the regional economy. Climate change impacts are being witnessed all over the world but the country like India is more vulnerable in view of its huge population, excessive pressure on natural resources and relatively weak coping mechanism. Expected effects of changes in global climate include warmer temperatures, rising sea levels, and potentially more frequent and extreme weather events such as hurricanes, tropical cyclones and heat waves. Climate change projections made for India indicate an overall increase in temperature by 1 to $4{ }^{\circ} \mathrm{C}$ and change in precipitation by 9 to
16\% toward 2050s (Kumar et al., 2011). Another significant aspect of climate change is the increase in the frequency of occurrence of extreme events such as droughts, floods, and cyclones. All of these expected changes will have adverse impacts on climate sensitive sectors such as agriculture, forest, coastal ecosystems and also on availability of water for different uses and on human health.

In countries like India where about 51 per cent of agriculture is under rain fed conditions, such variations have direct impact on regional economy (Department of Agriculture, Cooperation and Farmers welfare, 2017). In account by keeping the present scenario of rain fed area, the study was conducted to find a correlation between average weather data of 39 years (1980 to 2018) and 2019.

\section{Materials and Methods}

The study was conducted with 39 years weather data viz. maximum and minimum temperature, rainfall, rainy days and relative humidity (7 AM and 2 PM) collected from SaheedGoondadhur College of Agriculture and Research Station, Jagdalpur, Bastar. Jagdalpur $\left(19.0854^{\circ} \mathrm{N}, 82.0183^{\circ} \mathrm{E}\right.$ and elevation of $552 \mathrm{~m}$ from sea level) has a tropical wet and dry climate (Köppen climate classification Aw) with three main seasons: summer, monsoon, and winter. Summers last from March to May and are hot, with the average maximum for May reaching $38.1{ }^{\circ} \mathrm{C}$. The weather cools off somewhat for the monsoon season from June to September, which features very heavy rainfall. Winter remains warm and dry.

\section{MS -Office}

MS - Excel software package is used to find out the correlation between average weather data of 38 years (1980 to 2018) and 2019. 


\section{Results and Discussion}

\section{Maximum and minimum temperature}

Average maximum and minimum temperature of 39 years $(1980-2018)$ and 2019 is listed in table 1. After manipulating data in MS -
Excel software package correlation between maximum temperatures shows 0.98207 . Monthly mean maximum temperature of 2019 varies from $27.2^{\circ} \mathrm{C}$ to $38.1^{\circ} \mathrm{C}$ in comparison to 1980 to 2018 which was recorded as 27.0 ${ }^{\circ} \mathrm{C}$ to $37.4{ }^{\circ} \mathrm{C}$ (Table $1-3$ ).

Table.1 Table of comparison of 1980 - 2018 (39 years) and 2019 maximum and minimum temperature data

\begin{tabular}{|c|c|c|c|c|}
\hline \multirow[t]{2}{*}{ Months } & \multicolumn{2}{|c|}{ Maximum Temperature } & \multicolumn{2}{|c|}{ Minimum Temperature } \\
\hline & $1980-2018$ & 2019 & $1980-2018$ & 2019 \\
\hline JAN & 27.9 & 27.2 & 10.3 & 8.8 \\
\hline FEB & 31.2 & 31.4 & 13.1 & 13.6 \\
\hline MAR & 34.2 & 34.9 & 17.5 & 18.6 \\
\hline APR & 36.7 & 37.6 & 21.6 & 21.2 \\
\hline MAY & 37.4 & 38.1 & 23.8 & 23.7 \\
\hline JUN & 32.5 & 34.8 & 23.4 & 24.6 \\
\hline JUL & 28.5 & 28.9 & 22.4 & 22.6 \\
\hline AUG & 27.9 & 28.7 & 22.3 & 22.4 \\
\hline SEP & 29.4 & 29.4 & 21.9 & 22.5 \\
\hline OCT & 29.7 & 30.2 & 18.8 & 20.9 \\
\hline NOV & 28.3 & 29.5 & 13.9 & 14.8 \\
\hline DEC & 27.0 & 28.1 & 9.8 & 12.5 \\
\hline Mean & 30.9 & 31.6 & 18.2 & 18.8 \\
\hline
\end{tabular}

Table.2 Table of comparison mean rainfall and rainy day values between 1980 - 2018 (39 year) and 2019

\begin{tabular}{|l|l|l|l|l|}
\hline & Rainfall & & Rainy days & \\
\hline Months & $\mathbf{1 9 8 0 - 2 0 1 8}$ & $\mathbf{2 0 1 9}$ & $\mathbf{1 9 8 0 - 2 0 1 8}$ & $\mathbf{2 0 1 9}$ \\
\hline JAN & 10 & 13 & 0.846 & 1 \\
\hline FEB & 7 & 0.2 & 0.974 & 0 \\
\hline MAR & 21 & 0.0 & 1.74 & 0 \\
\hline APR & 45 & 41.5 & 3.871 & 3 \\
\hline MAY & 76 & 89.8 & 5.205 & 5 \\
\hline JUN & 239 & 221.0 & 11.02 & 9 \\
\hline JUL & 338 & 622.5 & 16.84 & 21 \\
\hline AUG & 359 & 582.2 & 17.53 & 22 \\
\hline SEP & 211 & 499.0 & 11.79 & 16 \\
\hline OCT & 87 & 237.8 & 8.674 & 11 \\
\hline NOV & 18 & 0 & 1.153 & 0 \\
\hline DEC & 6 & 6 & 0.421 & 0 \\
\hline Mean & $\mathbf{1 4 1 6 . 8}$ & $\mathbf{2 3 1 3}$ & $\mathbf{8 0 . 0 9 5}$ & $\mathbf{8 8}$ \\
\hline
\end{tabular}


Table.3 Table of comparison of relative humidity between 1980 - 2018 (39 year) and 2019

\begin{tabular}{|l|l|l|l|l|}
\hline & RH I & & RH II & \\
\hline Months & $\mathbf{1 9 8 0}-\mathbf{2 0 1 8}$ & $\mathbf{2 0 1 9}$ & $\mathbf{1 9 8 0}-\mathbf{2 0 1 8}$ & $\mathbf{2 0 1 9}$ \\
\hline JAN & 87 & 93 & 41 & 31 \\
\hline FEB & 81 & 87 & 35 & 32 \\
\hline MAR & 71 & 81 & 29 & 31 \\
\hline APR & 66 & 69 & 30 & 30 \\
\hline MAY & 65 & 72 & 35 & 37 \\
\hline JUN & 78 & 80 & 59 & 55 \\
\hline JUL & 89 & 93 & 76 & 78 \\
\hline AUG & 89 & 94 & 78 & 77 \\
\hline SEP & 89 & 94 & 71 & 75 \\
\hline OCT & 87 & 96 & 61 & 67 \\
\hline NOV & 86 & 97 & 52 & 46 \\
\hline DEC & 86 & 97 & 46 & 42 \\
\hline Mean & $\mathbf{8 1 . 2}$ & $\mathbf{8 7 . 7}$ & $\mathbf{5 1 . 1}$ & $\mathbf{5 0 . 0}$ \\
\hline & & & & \\
\hline
\end{tabular}

Graph.1 Plotted graph of comparison between maximum temperature $1980-2018$ (39 years) and 2019

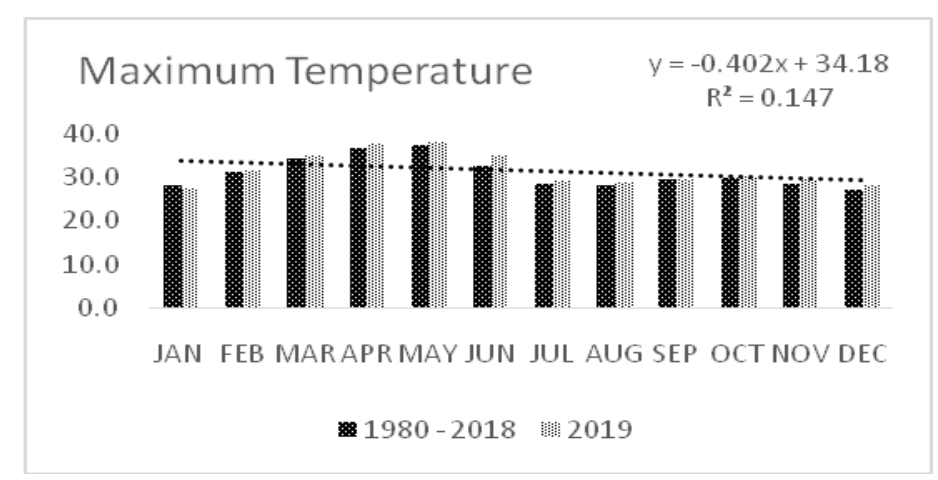

Graph.2 Plotted graph of comparison between minimum temperature 1980 - 2018 (39 years) and 2019

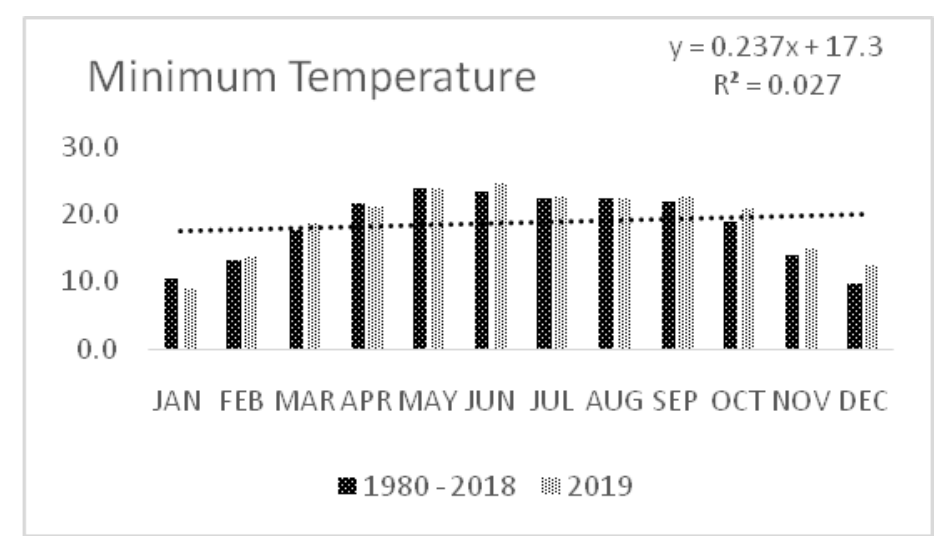


Graph.3 Plotted graph comparison mean rainfall and rainy day values between 1980 - 2018 (39 year) and 2019

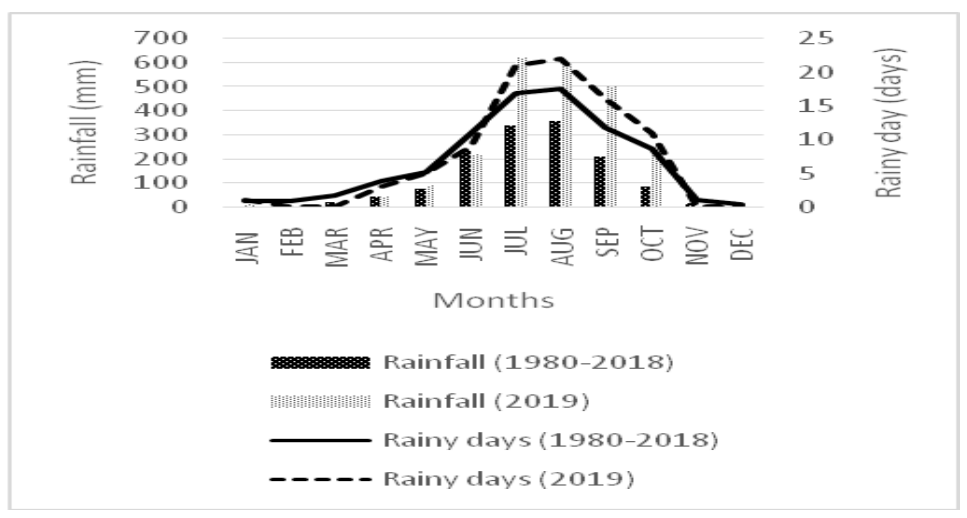

Graph.4 Trend analysis of comparison of relative humidity (7 AM) between 1980 - 2018 (39 year) and 2019

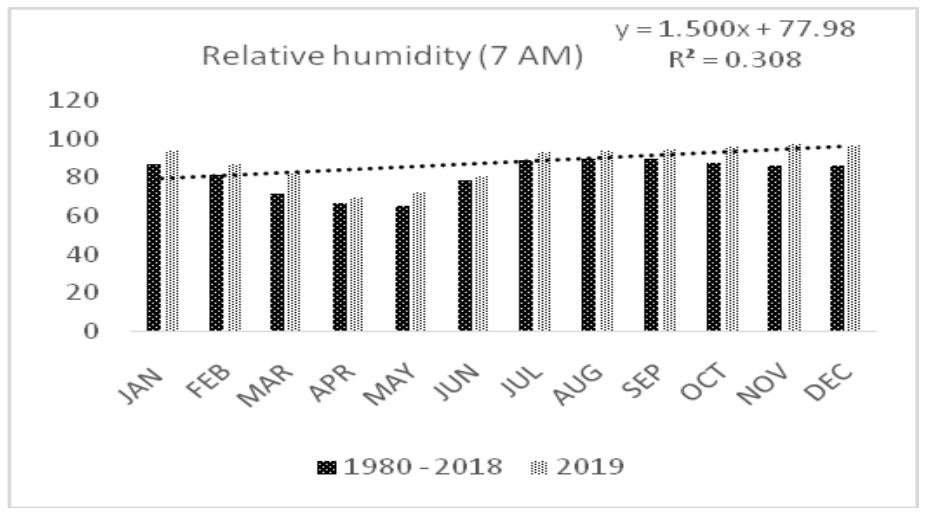

Graph.5 Trend analysis of comparison of relative humidity (2 PM) between 1980 - 2018 (39 year) and 2019

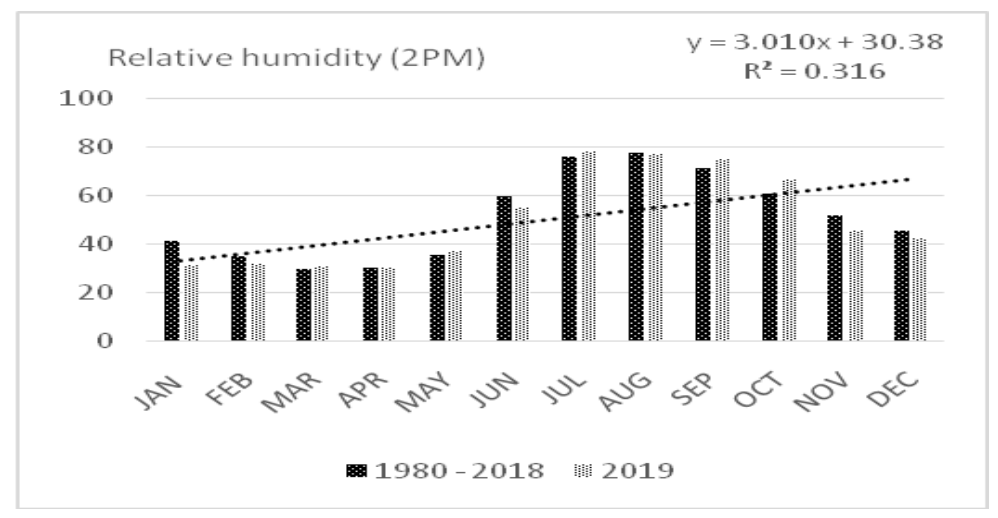

Highest maximum temperature is recorded in the month of May in both the years and lowest maximum temperature is recorded in month of December in 1980 to 2018 and in January in 2019. Likewise monthly mean minimum temperature ranges from $8.8{ }^{\circ} \mathrm{C}$ to 
$24.6^{\circ} \mathrm{C}$ in year 2019 and $9.8^{\circ} \mathrm{C}$ to $23.8^{\circ} \mathrm{C}$ in 1980 to 2018. Mean minimum temperature slightly increases $\left(0.6{ }^{\circ} \mathrm{C}\right)$ in 2019 as compared to mean minimum temperature of 1980 - 2018 and correlation between them shows 0.9771. Highest temperature is recorded in May - July and lowest is recorded in December - January.

Both maximum and minimum temperature shows an increasing change in year 2019 from previous years.

\section{Rainfall and rainy days}

Long-term analysis of rainfall data (19802018) indicated that Jagdalpur receives a mean annual rainfall of $1416.8 \mathrm{~mm}$ during past 39 years and as low as $994 \mathrm{~mm}$ during 1997 to as high as $2285.9 \mathrm{~mm}$ during 1990. Maximum mean rainfall in last 39 years is recorded in month of August with $359 \mathrm{~mm}$, but in 2019 maximum mean rainfall is recorded in month of July with $623 \mathrm{~mm}$. The rainfall is recorded more in 2019 as compared to previous years $(1980-2018)$ with mean values of $2313 \mathrm{~mm}$ and $1416.8 \mathrm{~mm}$ respectively. The correlation values between them was 0.9446. Mean rainfall for the year 2019 is recorded more.

Annual rainy days (rainfall $>2.5 \mathrm{~mm}$ in a day) varied widely from 58 (in 2002) to as high as 116 (in 2012). Also maximum rainy day was seen in month of August for both the years i.e. $17.53(\sim 18)$ days in past 39 years (1980-2018) and 22 days in 2019.

Mean relative humidity of 1980 to 2018 ranges from 51.1 to 81.2 as compared to mean relative humidity of 2019 which was recorded 50.0 to 87.7. Correlation between RH I was shown 0.9505 and RH II was 0.9739 .

In conclusion the result of above experiment shows that all the weather parameters are in increasing trend in year 2019 except evening relative humidity (RH II) which shows a nominal decreasing trend, as compared to previous 38 years. This study shows that required precautions should be done to overcome from the fluctuation of weather parameters.

\section{References}

Allen, R., Pereira, L.A., Raes, D. and Smith, M. (1998). Crop Evapotranspiration. FAO Irrigation and Drainage. Paper no. 56. Food and Agricultural Organization of the United Nations, Rome, Italy, 293 pp.

Choudhury, B.U., Das, A., Ngachan, S.V., Slong, A., Bordoloi, L.J. and Chowdhury, P. (2012). Trend analysis of longterm weather variables in midaltitude Meghalaya, North- East India. J. Agril. Physics, 12:12-22.

CSSRI, NAIP. (2014). Final Report of NAIP sub-project on Strategies for Sustainable Management of Degraded Coastal Land and Water for Enhancing Livelihood Security of Farming Communities. ICAR-Central Soil Salinity Research Institute, Regional Research Station, (CSSRI, RRS), Canning Town - 743 329, India. p. 104.

IPCC. (2007). IPCC (Intergovernmental Panel on Climate Change), Climate Change 2007. Fourth Assessment Report. Cambridge University Press, Cambridge, UK.

Kumar, K., K., Kamala, K., Rajagopalan, B., Hoerling, M.P., Eischeid, J.K., Patwardhan, S.K., Srinivasan, G., Goswami, B.N. and Nemani, R. (2011). The once and future pulse of Indian monsoonal climate. Clim. Dynamics, 36(11): 2159-2170.

Mandal, S., Choudhury, B.U., Mandal, M. and Bej, S. (2013). Trend analysis of 
weather variables in Sagar Island, West Bengal, India: a long-term perspective (1982-2010). Current Sci. 105(7): 947-953.

Mandal, U.K., Maji, B., Mullick, S., Nayak, D.B., Mahanta, K.K. and Raut, S. (2019a). Global climate change and human interferences as risk factors, and their impacts on geomorphological features as well as on farming practices in Sundarbans eco-region. In: Sundarbans a trans-boundary dynamic and disaster-prone ecosystem, Sen, H.S., (ed.), Springer International Publishing AG, Cham, pages 405-437.
Mandal, U.K., Burman, D., Bhardwaj, A.K., Nayak, D.B., Samui, A., Mullick, S., Mahanta, K.K., Lama, T.D., Maji, B., Mandal, S., Raut, S. and Sarangi, S.K. (2019b). Waterlogging and coastal salinity management through land shaping and cropping intensification in climatically vulnerable Indian Sundarbans. Agril. Water Manage. 216: $12-26$.

Mandal, U.K. and Nayak, B.D. (2019). Trend analysis of weather parameters over Indian Sundarbans. Journal of Agrometeorology 21 (3): 307-315

\section{How to cite this article:}

Kumar, M., A. Sanadya, J. L. Choudhary, G. K. Das and Nada, H. C. 2020. Comparison of Current Year (2019) Meteorological Parameters on the Basis of Long Term Climate Data of Bastar District. Int.J.Curr.Microbiol.App.Sci. 9(11): 136-142.

doi: https://doi.org/10.20546/ijcmas.2020.911.016 